\title{
OFENSIVA À CIFRA DOURADA DA CRIMINALIDADE: UM OLHAR CRIMINOLÓGICO acerca da atuação da Polícia Federal no INÍCIO DO SÉCULO XXI
}

Fábio Caram Meireles

Polícia Federal - MG

\section{RESUMO}

Perpassa pela história de formação e conformação do Brasil a noção criminológica de que, a despeito de a cultura jurídica nacional ser fundada em uma pretensa igualdade, há um impetuoso viés discriminatório no que tange ao tratamento igualitário material nos âmbitos criminal e penal para a população como um todo. Paulatinamente, as vicissitudes sociais têm promovido uma aproximação da igualdade formal com a material, entre as quais uma reformulação seletiva da atuação dos órgãos de persecução criminal, com vistas à legitimação da atuação repressiva estatal sob a égide do império da lei. Este artigo demonstra, com a contribuição do lastro teórico criminológico, como a Polícia Federal (PF) tem alterado o seu panorama técnico-investigativo, bem como as consequências desta novel atuação na tessitura social.

Palavras-chave: polícia; direito; criminologia; colarinho branco; criminalidade econômica.

\section{INTRODUÇÃo}

É majoritária no Brasil a concepção positivista do Direito, assevera o professor emérito da Universidade de São Paulo-SP (USP) Dalmo de Abreu Dallari (2000), perspectiva segundo a qual "sóédireito o que está na lei e estando na lei é justo e legítimo, escamoteando-se o fato de que a lei tem sido feita pelos dominadores e privilegiados ou por seus agentes, sempre dando preferência aos interesses e às conveniências desses grupos" (DALLARI, 2000, p. 480). O jurista explicita que ainda nos dias de hoje há membros do Legislativo, do Executivo e do Judiciário que agem como protetores dos interesses dos que ocupam o topo da pirâmide social e buscam, sobretudo, a garantia dos privilégios patrimoniais dos dominadores, além de sua impunidade nos âmbitos civil, fiscal e penal. 
Assim, também é histórica a enorme distância entre o direito que se encontra nas leis e aquele que se aplica na prática. E as concepções jurídicas tradicionalmente predominantes nunca se preocuparam com esse aspecto, fixando-se quase que exclusivamente nas doutrinas e nos textos legais, ignorando a realidade. [...] E o Poder Judiciário, muito preso ao formalismo abstrato dos textos legais e submisso a sistemas processuais excessivamente minuciosos, propícios à discussão e rediscussão de pormenores técnico-jurídicos, age com grande lentidão e se preocupa mais com a legalidade formal do que com a justiça. Daí o distanciamento entre o direito formal e o real (DALLARI, 2000, p. 482).

Outrossim, acerca de tratar desigualmente os desiguais, o livre docente do Departamento de Sociologia da USP Marcos César Alvarez (2002) aponta que é necessário estender a igualdade de tratamento para o conjunto da população e repensar as práticas discriminatórias ainda presentes no campo jurídico-criminal-penal do País, porquanto os operadores do Direito pátrio têm atribuído "graus diferenciados de cidadania a setores distintos da população" (ALVAREZ, 2002, p. 699).

No mesmo diapasão, o advogado, político e doutrinador Nilo Batista (1990) critica:

Quando alguém fala que o Brasil é 'o país da impunidade', está generalizando indevidamente a histórica imunidade das classes dominantes. Para a grande maioria dos brasileiros - do escravismo colonial ao capitalismo selvagem contemporâneo - a punição é um fato cotidiano" (BATISTA, 1990, p. 38).

Portanto, cristalizaram-se nas relações interpessoais e, por conseguinte, no imaginário coletivo práticas discriminatórias que desequilibram o princípio da igualdade material, particularmente nas instituições de policiamento, "em que o pobre se torna sobremaneira o foco de atenção da polícia, uma 'polícia de propriedade"' (LEE apud YOUNG, 2010, p. 12).

\section{Polícia, estado e sociedade}

Etimologicamente advindo do termo grego politeia, o qual designava, em sentido geral, a ciência dos fins e deveres do Estado, a par- 
tir do século XVIII estabelece-se na Europa a noção de Polícia como corporação (força de segurança) encarregada pela ordem pública, conforme precisa o professor de Direito da Universidade do PortoPOR António Francisco de Sousa (2009).

Modernamente, a característica fundamental do Estado moderno, segundo o sociólogo Max Weber (1997), é “[...] o monopólio do uso legítimo da força física dentro de determinado território" (WEBER, 1997, p. 14). O professor de Justiça Criminal da Universidade de Nova Iorque-EUA David Bayley (2006), por sua vez, define polícia a partir da tríade formada por força física, uso interno e autorização coletiva: "pessoas autorizadas por um grupo para regular as relações interpessoais dentro deste grupo através da aplicação de força física" (BAYLEY, 2006, p. 20).

Já Sousa aduz que: "A polícia consiste na acção [...] da Administração Pública de protecção da comunidade contra os perigos que a ameaçam, se necessário através do recurso à coacção, tendo em vista a ordem e segurança públicas" (SOUSA, 2009, p. 14). Desse modo, polícia é a instituição que carrega em si, de modo imanente, o monopólio executivo do uso da força.

Como se analisará mais detidamente em tópico próprio, sob o viés criminológico, o professor de Direito Penal da Universidade Estadual de Santa Cruz-BA Eduardo Viana (2017) pontua que a atividade policial está inserida no controle social formal - regulativo -, do qual fazem também parte outras instituições estatais de controle da criminalidade, como administração penitenciária, Ministério Público e Juiz.

"Entre as instituições da área da justiça e segurança pública, a polícia é uma espécie de 'gata borralheira', jamais convidada para os bailes dos teóricos, mas sempre muito comentada por eles” (BATISTA, 1990, p. 170). De acordo com Nilo Batista, para se conceber uma polícia instituída sob os auspícios do Estado Democrático de Direito, há que se romper com uma perspectiva policial reducionista simplesmente analisada sob o binômio: violência-corrupção, a qual engendra uma perniciosa espiral de isolamento e abandono para as agências de segurança pública. 
Não obstante, as organizações policiais e o ambiente estão em permanente transação, como cita o acadêmico e então diretor da Polícia de Segurança Pública de Portugal Paulo Valente Gomes (2010): "Este conceito sistémico significa que a Polícia afecta e influencia o contexto externo e, ao mesmo tempo, é afectada e influenciada pelo ambiente" (GOMES, 2010, p. 118).

Por seu turno, o professor da Universidade de Frankfurt-ALE Hans-Gerd Jaschke (apud ALMEIDA, 2010) corrobora que a atividade policial tem por base o conhecimento e a ciência. Nesse diapasão, o mestre em Direito das Relações Sociais pela Pontifícia Universidade Católica de São Paulo-SP Welder Oliveira de Almeida aduz que: "Os servidores policiais necessitam, cada vez mais, de uma formação e conhecimentos minuciosos a respeito dessa atividade e de seus desafios colocados por uma realidade cada vez mais dinâmica e globalizada" (ALMEIDA, 2010, p. 141).

A polícia precisa ser integral, salienta Gomes, no sentido de se tornar "agregadora de múltiplas valências e capacidades e beneficiando das sinergias daí decorrentes, para que possa aspirar a uma melhor compreensão e actuação sobre uma realidade também ela complexa e multifactorial" (GOMES, 2010, p. 120).

Retomando as ideias de Nilo Batista (1990), referido autor assevera que o serviço policial prestado sob o influxo do Estado de Direito deve contemplar cinco características fundamentais: prevenção (planejamento prévio e articulação com demais planos administrativos), eficácia (foco na raiz dos problemas e desburocratização), legalidade (observância estrita da lei), socialidade (acesso e atendimento democrático) e comunitariedade (estabelecimento de permanente e transparente diálogo com a sociedade organizada, por meio da divulgação periódica de estatísticas, a fim de permitir correções na forma de atuação).

\section{RELEVÂNCIA DO SABER CRIMINOLÓGICO}

Crítico da atomização da ciência criminológica em compartimentos estanques, com dispersão por especialidades, sem uma perspectiva do todo, o professor de Direito Penal e Criminologia da 
Universidade Nacional de Buenos Aires-ARG Carlos Alberto Elbert (2011) propóe a definição da criminologia em um contexto de validez genérica, dentro do qual seja possível obter coerência, continuidade e lógica discursiva. "Cada fragmento permanece ensimesmado em temáticas específicas, tais como drogas, menores, prisões, segurança, vítimas, gênero etc., sem qualquer esforço para transcendê-las e insertálas em uma visão teórica geral" (ELBERT, 2011, p. 2).

A despeito de não possuir a ciência criminológica um estatuto próprio monolítico, com especificidade metodológica e precisão objetiva, há progressos adquiridos pela disciplina no plano epistemológico, os quais promovem a reflexão da própria atuação dos órgãos de controle.

Sob o olhar criminológico delineado pela abordagem da rotulação (labeling approach), o conceito de crime é consequência da reação social do sistema penal ao fato, estando a explicação do fenômeno criminal nas respostas formais do Estado para determinado comportamento. "O delito (a desviação) não é uma qualidade da conduta, mas sim uma etiqueta atribuída a partir de complexos processos de interação social" (VIANA, 2017, p. 264). Desse modo, o que estaria em foco não seria a conduta desviante por si só, mas a forma como as agências formais de controle, polícia inserida, filtram e reagem ao referido comportamento.

\subsection{GARANTISMO PENAL}

O professor da Universidade de Roma-ITA Luigi Ferrajoli (2002), formulador da teoria geral do garantismo penal institui os princípios fundantes do sistema garantista (SG), denominados axiomas, que estariam harmonizados sistematicamente, entre os quais se destacam, sobremaneira na atuação policial: os princípios da lesividade (efetiva ofensa ao bem juridicamente protegido), da materialidade (prova da existência do delito) e da culpabilidade (devida e segura comprovação da culpa do autor).

O modelo garantista descrito em SG apresenta as dez condições, limites ou proibições que identificamos como garantias do cidadão contra o arbítrio ou o erro penal. Segundo este modelo, não 
se admite qualquer imposição de pena sem que se produzam a comissão de um delito, sua previsão legal como delito, a necessidade de sua proibição e punição, seus efeitos lesivos para terceiros, o caráter externo ou material da ação criminosa, a imputabilidade e a culpabilidade do seu autor e, além disso, sua prova empírica produzida por uma acusação perante um juiz imparcial, em um processo público e contraditório em face da defesa e mediante procedimentos legalmente preestabelecidos (FERRAJOLI, 2002, p. 83).

Destarte, a teoria garantista, a fim de elidir o arbítrio estatal e promover a dignidade da pessoa humana, se estabelece como limitação e conformação do direito penal e do direito processual penal à Constituição. No prefácio da obra Direito e Razão, o filósofo Norberto Bobbio chama a atenção para a construção das vigas-mestras do Estado de Direito que possuem por base tutelar a liberdade do cidadão contra o abuso de poder advindo da aplicação do jus puniendi estatal com irracionalidade e ilegalidade. "Deslegitimar o exercício absoluto da potestade punitiva” (FERRAJOLI, 2002, p. 73) - esta seria a função das garantias no direito criminal, uma faceta menos permissiva ou legitimadora e mais condicionante ou vinculadora.

Verifica-se uma negação ao abolicionismo penal ao se tomar por base o Direito Penal como tutela subsidiária de bens jurídicos valiosos, a partir da atuação pujante da polícia e seu instrumental investigatório dos delitos econômico-financeiros cometidos por organizações criminosas que se imiscuem junto ao Estado e praticam condutas que atingem a coletividade como um todo.

\subsection{COLARINHO BRANCO}

Termo cunhado pelo sociólogo norteamericano Edwin Sutherland (1999), nos idos de 1939, o crime de colarinho branco sustentou o desenvolvimento da teoria da aprendizagem social, segundo a qual o comportamento delituoso seria o resultado de um processo de aprendizado interacional entre indivíduos criminosos partilhadores de interesses e valores comuns.

Em virtude de se relacionar a métodos complexos e transações sofisticadas, o crime de colarinho branco - white collar crime -, rece- 
beu essa designação por ser cometido a priori sem violência e usualmente envolver pessoas com expressiva influência socioeconômica, ocupantes de cargos ou funções de elevado grau de respeitabilidade social, as quais trajam vestuário com rigor aristocrático (SALGADO, 2010).

O professor da Universidade Complutense de Madri-ESP Antonio García-Pablos de Molina (1984) anunciou, em meados da década de 1980, que o que se pretendia denunciar com o conceito de delinquente de colarinho branco era algo grave: "Es la particular trascendencia social de los crímenes de los poderosos, en compareción con la criminalidad convencional, y la irritante impunidad de que, sin embargo, suelen disfrutar en nuestro tiempo"I (MOLINA, 1984, p. 179).

Por sua vez, o docente da Faculdade de Direito da Fundação Getúlio Vargas Rodrigo de Grandis (2010) nota que a danosidade social dos delitos tradicionais é restrita, enquanto que o efeito deletério da delinquência do colarinho branco é sensivelmente mais acentuado, uma vez que esta modalidade delituosa, além de comprometer a idoneidade da ordem econômica (eliminação da concorrência, desconfiança nas relações mercantis, deformação do equilíbrio do mercado etc.), ainda ocasiona consequências devastadoras à coletividade (vida e saúde da população como um todo) e até mesmo à ordem jurídica internacional.

Crimes contra o sistema financeiro nacional (Lei 7.492/86) e de "lavagem" de recursos ilícitos (Lei 9.613/98) segundo de Grandis, se praticados na conjuntura de uma organização criminosa bem estruturada e influente, "possuem a aptidão de atingir, de modo indelével, toda a ordem econômica de um país, a depender da conduta perpetrada" (GRANDIS, 2010, p. 376).

\subsection{Cifra dourada}

Relacionada à criminalidade oculta de viés econômico, não registrada nas estatísticas oficiais, a cifra dourada representa a criminalidade do colarinho branco, "definida como práticas antis-

1 É a particular transcendência social dos crimes dos poderosos, em comparação com a criminalidade convencional, e a iritante impunidade de que, no entanto, costumam desfrutar em nosso tempo (tradução livre do autor). 
sociais impunes praticadas por aqueles que detêm o poder político e econômico (em nível nacional e internacional), em prejuízo da coletividade e dos cidadãos e em proveito das oligarquias econômico-financeiras" (VIANA, 2017, p. 162).

Ademais, a desmaterialização da vítima na sociedade contemporânea, em que o delito lesiona ou expõe a perigo de lesão bens jurídicos cuja titularidade não é de determinada pessoa, mas toda a coletividade, é denominada vitimização difusa. Segundo Viana, esse processo "[...] tem o inconveniente de não transmitir à consciência coletiva a gravidade de tais delitos. Com efeito, a ausência de uma vítima identificada - com a qual a sociedade se solidariza - maquia a relevância da conduta, a tal ponto de considerá-la desmerecedora da tutela penal" (VIANA, 2017, p. 161).

Nessa linha, o professor da Escola Superior do MPU Daniel Salgado (2010) propugna que há "resistência à adequação de meios investigativos às modernas formas de criminalidade, dentre elas a delinquência econômica" (SALGADO, 2010, p. 61), sendo tal relutância alicerçada por meio de críticas tendenciosas da instituição, na persecução criminal, de um pretenso Estado policialesco. Para o autor, o estabelecimento de restrições legais ao rol de legitimados a procederem a diligências investigatórias, bem como a manutenção de anacrônicos instrumentos de investigação, dissimulam o fenômeno da política de "interesses encobertos", denominação cunhada pelo docente da Universidade de Munique-ALE Bernd Schünemann. Para Salgado, esta política mantém o status quo de beneficiar a delinquência econômica, garantindo privilégios às classes mais abastadas, porquanto “[...] o legislador continua a utilizar a criação normativa penal como apanágio de uma desigualdade substancial histórica" (SALGADO, 2010, p. 62).

Propõe Salgado não apenas uma mudança na cultura legislativa, mas um giro hermenêutico para a superação de um discurso penal liberal exorbitante por meio de uma concepção de direito calcada em um Estado de Justiça Social. No âmbito da delinquência econômica, tanto quanto nas condutas de sonegação fiscal, evasão de divisas, gestões temerárias e fraudulentas, os mecanismos processuais ainda seriam interpretados sob o influxo liberal das implicações pessoais que o criminoso sofreria, mitigando o enfrentamento da macrocriminalidade e atenuando sobremaneira a persecução criminal à elite do crime. 
[...] novos métodos de investigação, necessários ao cabal acesso a elementos que formariam o quadro probatório de infrações penais identificadas com a delinquência econômica [...], são taxados de invasivos, excessivos ou imorais e, consequentemente, objetos de restrição, especialmente pelos Tribunais Superiores" (SALGADO, 2010, p. 63-64).

Nos tempos hodiernos, portanto, a repercussão da criminalidade econômica gestada na complexidade da sociedade moderna rompeu com o paradigma das relações jurídicas meramente interindividuais para afligir objetividades jurídicas difusas, como na ocorrência de corrupção corrosiva, lavagem vultosa de dinheiro e grandes escândalos financeiros. $\mathrm{O}$ autor infere que se faz necessária a adaptação do direito, sob o prisma da defesa social, às mudanças da realidade fática, promovendo-se uma releitura do sistema penal sem, entretanto, olvidar das garantias penais do Estado de Direito: "As garantias não só permanecem intactas, mas, por enxertá-las de conteúdo de justiça material, são superiores às conferidas no Estado Liberal" (SALGADO, 2010, p. 68).

No estado social de Direito, as garantias só podem ser derivadas e compreendidas a partir de princípios normativos, mas de base necessariamente ontológica, cheios de conteúdos materiais de igualdade e justiça social, e em absoluto são meras formas liberais que, até agora, funcionaram materialmente só e exclusivamente a serviço da definição, classificação, disciplina e repressão do comportamento desviado de classes sociais economicamente despossuídas e, por isso, politicamente dominadas e subjugadas, e a serviço, ao mesmo tempo, da exclusão do discurso da criminalidade de quase totalidade da criminalidade material das classes sociais poderosas [...]" (MARTIN, 2006, p. 145).

Destarte, para o professor de Direito Penal da Universidade de Zaragoza-ESP Luis Gracia Martin (2006), os delitos econômicos perpetrados pela elite, portadores de "danosidade social exponencial e de magnitude cósmicas", devem ser debelados pelo fortalecimento de mecanismos aptos ao seu enfrentamento, já que os crimes tradicionais, comparativamente, assumem a conotação de bagatela. 


\title{
4. OFENSIVA À CRIMINALIDADE ECONÔMICA
}

\begin{abstract}
"É lugar comum, em criminologia, referir-se à distância estrategicamente mantida, no campo da criminalidade econômica e financeira, entre condutas desviantes e condutas delituosas. [...] Tal distância, no terreno da 'delinquência dourada' é estável e permanente demais para ser também inocente; e ainda quando rompida no plano legislativo, não se encurta na prática do sistema penal" (BATISTA, 1990, p. 44).
\end{abstract}

Segundo Nilo Batista, a incorporação da distância entre o desviante e o delituoso nos crimes do colarinho branco costuma levar à dessensibilização do sistema penal, fazendo com que ninguém se mexa e nada aconteça.

Ainda na década de 1990, Batista assinalou ser óbvio que a legislação criminal deveria ser reformulada para reduzir a distância entre a forte reprovação comunitária e seus dispositivos, atenuando a crise de funcionalidade gerada, assim como também seria claro que todos os níveis do sistema penal e de suas conexões administrativas, teriam que "recondicionar seus sensores para os crimes dos poderosos, que são cometidos à sua frente sem que nada aconteça; e a crise, aqui, não é funcional e sim política e moral" (BATISTA, 1990, p. 46).

Observa Shünemann (apud VIANA, 2017) que nas últimas décadas a Alemanha tem alterado o paradigma do direito penal da classe baixa para o da classe alta em razão de uma exigência moral, tendendo à construção de tipos penais criminalizadores de condutas praticadas por pessoas ocupantes de elevado status social-econômico.

Mas para o professor da Escola Superior do Ministério Público da União-DF, Douglas Fischer (2001), "não se tem difundido no Brasil que Ferrajoli reconhece expressamente o desenvolvimento de uma nova criminalidade, 'de la cual provenien las ofensas más graves a los derechos fundamentales: la criminalidad del poder"'2 (FISCHER, 2001, p. 31).

No que concerne às consequências dos delitos econômicos (e os custos sociais deles decorrentes), temos plena tranquilidade em

2 da qual provêm as mais graves ofensas aos direitos fundamentais: a criminalidade do poder (tradução livre do autor). 
assentar que, regra geral (sob a ótica dos resultados econômicos), possuem os efeitos mais lesivos se comparados com aqueles da delinquência tradicional. (FISCHER, 2001, p. 35)

Viana também afiança tal entendimento: “[...] enquanto há uma visível preferência de classe social para criminalização primária, legislador e jurisprudência insistem em afastar a classe alta do Direito Penal" (VIANA, 2017, p. 347).

Entretanto, é perceptível a existência de uma ruptura com o embate à criminalidade clássica, de etiquetamento somente direcionado às classes sociais despojadas. O fenômeno de alteração do paradigma procedimental também é notável quando se verifica a ação da Polícia Federal do Brasil.

\subsection{Trabalho repressivo da Polícia Federal}

Da tônica de repressão ao descaminho e contrabando nos anos 1980, passando pelo combate ao tráfico ilícito de drogas na década de $1990^{3}$, a partir do ano 2000 nota-se uma predominância da atuação da PF no enfrentamento de crimes envolvendo organizações criminosas que atuam imiscuídas ao Poder. O Estado figura como ator estratégico para a dinâmica da criminalidade organizada, vez que grupos criminosos utilizam-no para maximização de seus objetivos: "Os atores estatais são, portanto, utilizados como ferramenta para facilitar as atividades criminais" (FELSON apud OLIVEIRA, 2012, p. 423).

Segundo o professor do Departamento de Ciência Política da USP Rogério Bastos Arantes (2011) o processo de reconstrução institucional da PF é tributário de deslocamentos de natureza dúplice, institucional e organizacional:

[...] de um lado, tais mudanças podem ser explicadas pelo desenho institucional capaz de propiciar resultados mais efetivos nas esferas criminal e federal; de outro, a maior efetividade depende também da motivação endógena e do empenho das organizações no aumento da eficácia de suas ações e no adensamento de suas relações recíprocas, na web of accountability, com vista a superar

3 Deflagração da Operação Alpha em 04/06/1994, considerada a primeira "Grande Operação da PF", a qual apreendeu 7,5 toneladas de cocaína em uma fazenda no município de Guaraí-TO.

Fonte: http://www.pf.gov.br/imprensa/grandes-operacoes 
o isolamento e a imprimir maior consequência às atividades de combate à corrupção (ARANTES, 2011, p. 99-100).

Outrossim, o professor da Escola Superior da Academia Nacional de Polícia-ANP/PF Célio Jacinto dos Santos (2017) aduz que a PF desenvolveu critérios operativos com o fito de delimitar o que se convencionou denominar "grandes operações de polícia judiciária", a partir da criação, em 2002, da Coordenação-Geral de Repressão ao Crime Organizado e de Inquéritos Especiais. Desse modo, a premissa operacional contempla os seguintes elementos: emprego de técnicas apuradas de investigação, com cooperação interinstitucional e internacional, contra ações criminosas de grande poderio econômico, social e político.

\section{Figura 1 - Estatística de operações ${ }^{4}$}

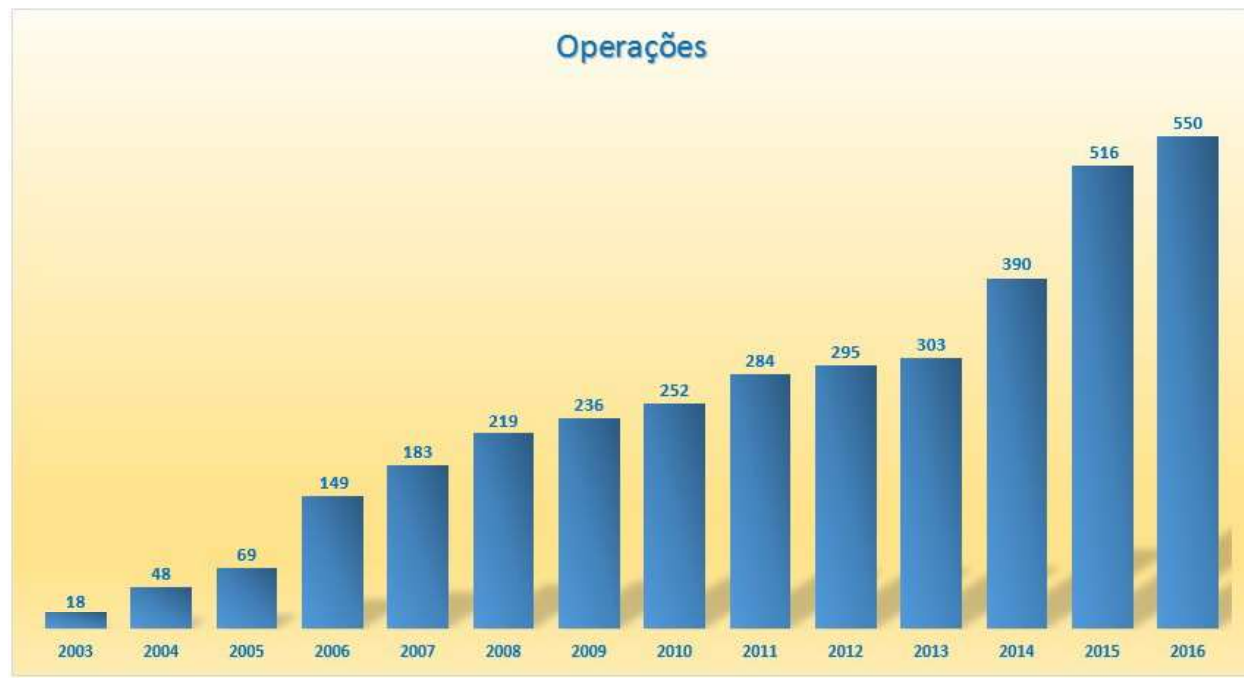

Fonte: sítio eletrônico da Polícia Federal.

[...] a repressão da criminalidade organizada - como as máfias e a corrupção cleptocrata - deve contar com meios necessários e proporcionais, que possibilitem o debelamento da ambição dos criminosos poderosos incrustados no aparelho estatal, e de organizações criminosas que causam danos à organização social (SANTOS, 2017, p. 17).

Como analisado anteriormente, as consequências provenientes dos mais variados tipos de corrupção envolvendo organizações criminosas, em especial nos crimes de desvio de verbas públicas e lavagem de dinheiro, são uma faceta perversa da impunidade, que exigem maior capacidade investigativa dos órgãos de controle.

4 Quantitativo anual das operações deflagradas pela PF entre os anos 2003 e 2016. 
Segundo o professor do curso de Direito da Universidade Federal do Paraná Sérgio Fernando Moro (2004), haveria ainda uma mentalidade da prática judicial condescendente com a corrupção, "prática que permite tratar com maior rigor processual um pequeno traficante de entorpecente [...] do que qualquer acusado por crime de 'colarinho branco', mesmo aquele responsável por danos milionários à sociedade" (MORO, 2004, p. 61).

Não obstante, a partir do progressivo aprimoramento das instituições responsáveis pela persecução criminal, em consonância com a repercussão social advinda da indignação pública para com a corrupção, observa-se no Brasil o fenômeno do fim da plena impunidade no que atine aos crimes de colarinho branco.

Além de uma hermenêutica de Direito Penal equilibrado das Cortes Superiores (vide mutação constitucional do STF, admitindo prisão a partir da decisão em segunda instância ${ }^{5}$ ) e de inovações legislativas (interceptação telefônica e telemática, ação controlada, infiltração policial, lei de "lavagem" de ativos e lei de combate às organizações criminosas e colaboração premiada ${ }^{6}$ ), a alteração paradigmática da atuação da PF é tributária também do aperfeiçoamento institucional do órgão.

As práticas desviantes realizadas por setores hegemônicos da sociedade que acarretam prejuízo à coletividade em benefício de oligarquias que convalidam seu poder e status social têm sido, hoje em dia, objeto sistemático de indignação pública, em razão da magnitude que tomaram, da alta reprovabilidade da conduta e dos graves impactos sociais que promovem (obras públicas paralisadas, investimento deficitário em saúde e educação, vias sem condições de trafegabilidade etc.).

A PF cumpre relevante função no combate a este tipo de modalidade criminosa, uma vez que possui competência constitucional para apurar infrações penais contra a ordem política e social, além da-

5 Processo $\mathrm{n}^{\circ}$ 8620448-89.2015.1.00.0000, referente ao julgamento do HC 126.292 em 17/02/2016.

6 Lei 9.296/1996 (que regulamenta o inciso XII, parte final, do art. $5^{\circ}$ da Constituição Federal, ao dispor sobre a interceptação de comunicações como meio de prova em investigação criminal e instrução processual penal), Lei 9.613/1998 com significativas alterações da Lei 12.683/2012 (que dispõe sobre os crimes de "lavagem" ou ocultação de bens, direitos e valores; a prevenção da utilização do sistema financeiro para os ilícitos previstos nesta Lei; cria o Conselho de Controle de Atividades Financeiras COAF) e Lei 12.850/2013 (que define organização criminosa e dispõe sobre a investigação criminal, os meios de obtenção da prova, infrações penais correlatas e o procedimento criminal). 
quelas cuja prática tenha repercussão interestadual ou internacional e exija repressão uniforme ${ }^{7}$.

Desse modo, ao saber que a investigação de qualquer crime de ação pública deva se proceder de ofício de modo obrigatório, conforme determinação legal ${ }^{8}$, mas reconhecer que não há capital humano e estrutura para tal, observa-se uma aplicação da abordagem da reação social sui generis, focalizando a criminalização de condutas desviantes praticadas pela elite, uma vez que possuem consequências deletérias para toda a coletividade, promovendo uma ofensiva contra a, até então, inatingível cifra dourada. Nesse sentido, "na busca de maior legitimidade, eficiência, eficácia, economia e ética (os 4 Es), o trabalho policial aposta cada vez mais numa abordagem holística, científica e flexível dos problemas" (GOMES, 2010, p. 111). E considerando que "arranjos institucionais distribuem poder diferenciadamente entre os atores políticos envolvidos no jogo" (NORTH apud OLIVEIRA, p. 423), aplica-se o princípio da seletividade no âmbito da investigação criminal, como catalisador da igualdade material a que se refere o introito.

\subsection{LEGITIMAÇÃo SOCIAL DO MODUS OPERANDI DA PF}

No moderno Estado de Direito, conforme leciona Sousa, não se pode conceber uma legalidade dissociada da legitimidade, ou seja, que seja totalmente independente. "Nesta medida, a legalidade também depende daquilo que a generalidade da população (a maioria da população - subjectividade social) considera ser correcto e justo" (SOUSA, 2009, p. 21). Legitimidade seriam os fundamentos materiais internos em que prevalece a correção e a justiça.

Para o filósofo associado à Escola de Frankfurt-ALE Jürgen Habermas (1997), a legitimidade da ordem jurídica não deve ir de encontro aos princípios morais: "o princípiodo direitolimita o princípio da moral e vice-versa. A legislação reflete-se na moral, a legalidade na moralidade, os deveres jurídicos nos deveres éticos" (HABERMAS, 1997, p. 139). Portanto, o autor raciocina que não há subordinação do direito positivo à moral, mas uma relação de complementariedade,

7 Art. 144 da CF/88.

8 Art. $5^{\circ}$ do CPP. 
constituindo-se o direito como um meio legítimo para assegurar autonomia dos cidadãos.

Outrossim, segundo Sousa, a atuação policial tem como princípio fundamental a juridicidade, uma vez que os poderes da polícia são adjudicados por lei e visam à finalidade pela legislação estabelecida: "Não há polícia sem lei ou à margem da lei e do Direito" (SOUSA, 2009, p. 47). Assim, para o estudioso em apreço, quanto ao domínio da persecução criminal, "sem fechar os olhos à realidade e sem retirar a eficácia da actuação policial, é indispensável que esta actuação, pelos perigos que representa para os direitos e liberdades dos cidadãos, seja uma actuação que exclua o arbítrio da autoridade" (SOUSA, 2009, p. 51).

Conforme já examinado, a utilização da ciência como fonte de conhecimento para o estudo do fenômeno criminal e para a atuação e gestão policial perante uma sociedade cada vez mais exigente é fator de legitimação social.

Bayley leciona que a atividade policial representa o uso de força da sociedade contra ela mesma: "Coerção, controle e opressão são sem dúvida necessários na sociedade, mas não são agradáveis" (BAYLEY, 2006, p. 18). E a partir desse aparente paradoxo que conforma a atividade da polícia, com viés dual entre necessidade e não-agradabilidade, delineia-se o modo pelo qual a sujeição às regras da lei é fator crucial na legitimação da autoridade da polícia.

Por sua vez, o professor da Universidade de Londres-ING Robert Reiner (2004), analisando a sociedade inglesa, aduziu que, paulatinamente, a nova polícia e o sistema de justiça criminal inseriram-se no cotidiano das classes menos favorecidas, não apenas sob a forma de controle de caráter repressivo, mas também como ferramenta com potencialidade restaurativa. Reiner propugna a adesão estrita da conduta policial ao ordenamento jurídico: "A forma pela qual a polícia mantinha a ordem e aplicava a lei supostamente deveria ser governada, ela mesma, por procedimentos legalistas e por restrições" (REINER, 2004, p. 88). Desse modo, infere-se que a legitimidade da atuação da polícia se dá, também, pelo consentimento social. "[...] nessa legitimação, o crescimento de um senso de eficácia da polícia foi, provavelmente, pelo menos tão significativo como os aspectos de construção de imagem" (REINER, 2004, p. 96). 
Já para Moro, a corrupção disseminada colocaria em xeque a legitimidade do próprio regime democrático:

A corrupção tende a espalhar-se enquanto não encontrar barreiras eficazes. O político corrupto, por exemplo, tem vantagens competitivas no mercado político em relação ao honesto, por poder contar com recursos que este não tem. Da mesma forma, um ambiente viciado tende a reduzir os custos morais da corrupção, uma vez que o corrupto costuma enxergar o seu comportamento como um padrão e não a exceção (MORO, 2004, p. 61).

O processo construtivo da imagem da PF na ofensiva contra a cifra dourada da criminalidade, disruptivo da abordagem da reação social clássica, e prospectivo da constituição do Estado Democrático de Direito, engendra-se por meio da legitimação da atividade policial como propulsor do controle social informal. Explica-se: a polícia, não obstante tradicionalmente enquadrada como uma agência instituída no controle formal da criminalidade, ao introjetar, de forma legítima, seu papel na comunidade pela assunção do novo modus operandi, tem proporcionado a transcendência na forma de controlar o crime. Propõe-se o raciocínio de que tal fenômeno ocorreria por meio do processo de socialização de valores morais e éticos, consubstanciados em normas e sanções sociais advindas do interacionismo simbólico. "Este controle social informal pode constituir excelente barreira à prevenção do comportamento desviante, seja porque atua, em regra, de modo preventivo, seja porque é capaz de impactar sobre a estruturação do controle interno do indivíduo" (VIANA, 2017, p. 171).

De acordo com Moro, a ação contra a corrupção só se mostra eficaz com o apoio da democracia e somente investigações e ações exitosas podem angariar a opinião pública. A atuação da $\mathrm{PF}$, quando percebida como legítima pela sociedade, conquistaria credibilidade popular, promove a justaposição dos controles formal e informal, e tende a estimular o declínio de comportamentos desviantes. 
Figura 2 - Índice de Confiança Social ${ }^{9}$

\section{ICS - Instituições}

\begin{tabular}{|c|c|c|c|c|c|c|c|c|c|c|}
\hline & 2009 & 2010 & 2011 & 2012 & 2013 & 2014 & 2015 & 2016 & 2017 & 2018 \\
\hline Corpo de Bombeiros & 88 & 85 & 86 & 83 & 77 & 73 & 81 & $\quad 83$ & 86 & $1 \quad 82$ \\
\hline 念 Igrejas & 76 & 73 & 72 & 71 & 66 & 66 & 71 & 67 & 72 & 66 \\
\hline [1] Policia Federal & & & & & & & & 66 & 70 & 65 \\
\hline 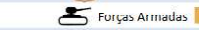 & 71 & 69 & 72 & 71 & 64 & 62 & 63 & 65 & 68 & 62 \\
\hline Escolas Publicas & 62 & 60 & 55 & 55 & 47 & 56 & 57 & 56 & 63 & 57 \\
\hline Policia & 52 & 52 & 55 & 54 & 48 & 48 & 50 & 52 & 57 & 53 \\
\hline Meios de Comunicação & 71 & 67 & 65 & 62 & 56 & 54 & 59 & 57 & 61 & 51 \\
\hline Iflit Empresas & 61 & 60 & 59 & 57 & 51 & 53 & 53 & 55 & 58 & 50 \\
\hline III Bantus & 61 & 58 & 57 & 50 & 48 & 50 & 49 & 50 & 59 & 50 \\
\hline Zanizações da Sociedade & 61 & 61 & 59 & 57 & 49 & 51 & 53 & 52 & 56 & 50 \\
\hline 귤 Ministério público & & & & & & & & 54 & 54 & 49 \\
\hline Poder Judiciário, Justiça & 52 & 53 & 49 & 53 & 46 & 48 & 46 & 46 & 48 & 43 \\
\hline Sistema Publico de Saúde & 49 & 47 & 41 & 42 & 32 & 42 & 34 & 34 & 41 & 38 \\
\hline 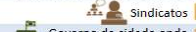 & 46 & 44 & $\square 4$ & 44 & 37 & 43 & 41 & 40 & 44 & W 35 \\
\hline $\begin{array}{l}\text { rno da cidade onde } \\
\text { mora }\end{array}$ & 53 & 50 & 47 & 45 & 41 & 42 & 33 & 32 & 38 & 34 \\
\hline Elin Eliçöes, sistema Eleitoral & 49 & 56 & 52 & 47 & 41 & 43 & 33 & W 37 & 35 & $\square 3$ \\
\hline Governo Federal & 53 & 59 & 53 & 53 & 41 & 43 & 30 & 36 & 26 & 25 \\
\hline - I - congresso Nacional & 35 & a 38 & 35 & 36 & 29 & 35 & 22 & 22 & 18 & 18 \\
\hline Wilien Portidos roliticos & 31 & 33 & 28 & 29 & 25 & 30 & 17 & 18 & 17 & 16 \\
\hline Presidente da República & 66 & 69 & 60 & 63 & 42 & 44 & 22 & 30 & 14 & || 13 \\
\hline
\end{tabular}

Fonte: Índice de Confiança Social de 2018 do Ibope.

Finalmente, como propugna o professor da PUC-SP Édson Luís Baldan (2018), em uma democracia, a iantituição Polícia nunca será algo fácil ou incontroverso:

[...] a começar porque a lei - e mesmo a ordem - cuja implementação cabe às polícias não é uma pauta de regras imutáveis, mas, ao revés, tanto as normas quanto a sua maneira de aplicação refletem compromissos em opiniôes e valores da sociedade, que os cria e anula" (BALDAN, 2018, p. 7).

Não obstante, a polícia deve apresentar valores e normas comprometidos com o Estado Democrático de Direito (BALDAN apud DAS; MARENIN, 2018, p. 8), contribuindo para a coesão social por meio do estabelecimento da confiança na atuação, posto que "numa democracia, o policiamento reflete e refrata o Estado e seus interesses, embora tais interesses sejam balanceados tanto em relação aos dos policiais quanto aos dos cidadãos" (BALDAN, 2018, p. 9). Portanto, a investigação criminal entabulada pela polícia deve resguardar as liberdades individuais e primar pela defesa pujante de um Estado em que eficiência e garantismo não se excluam, mas se limitem mutuamente, "materializando o princípio democrático como forma de legitimação do poder, para que se torne o impulso dirigente de uma sociedade" (BALDAN, 2018, p. 9).

9 A PF é considerada, desde 2016, a terceira instituição mais confiável do Brasil, à frente de Forças Armadas, Meios de Comunicação, Organizações das Sociedade Civil, Ministério Público e Poder Judiciário. 


\section{Consideraçốes finais}

Com atuação em âmbito nacional e sujeita a menor interferência $^{10}$ do que as Unidades da Federação na sua relação com o Executivo, a PF priorizou o investimento em inteligência e análise policial em seu "Plano Estratégico 2010/2022"11, promovendo um recrudescimento na investigação de organizações criminosas que atuam dentro do Estado $^{12}$ e13, solapando-o. Soma-se a isso o ingresso de quadros com formação multidisciplinar dos mais diversos ramos acadêmicos, via disputado concurso público ${ }^{14}$, e a promoção de capacitação permanente nas áreas de crimes financeiros e lavagem de dinheiro ${ }^{15}$.

Ao verificar que a impunidade não está institucionalizada para os detentores de poder, a partir da ofensiva à cifra dourada empreendida pela PF, o comportamento humano, inseparável dos intrincados processos sociais de interação e aprendizado, é influenciado pela atribuição de significados de valor ou desvalor de condutas por meio do construtivismo social.

Contudo, a partir do momento em que o sistema penal passou a atingir quem antes jamais fora atingido (a denominada criminalidade do colarinho branco), o professor da Escola Superior do MPU Bru-

10 Decretos 6.944/2009 e 8.326/2014.

11 Portaria $^{\circ}$ 4453/2014-DG/DPF.

12 Levantamento da Polícia Federal, feito a pedido do Jornal Correio Braziliense aponta que as ações da PF contra corrupção cresceram $411 \%$ em cinco anos, período em que o total de prisões chega a 1.946 e a de operações, a 621 . "Centenas de pessoas foram presas por cometer crimes como corrupção, formação de quadrilha, lavagem de dinheiro, fraude, obstrução da Justiça e recebimento de vantagem indevida, entre outros."

13 Segundo dados levantados pelo jornal O Globo junto à Coordenação-Geral de Repressão à Corrupção e à Lavagem de Dinheiro da Polícia Federal, o órgão promoveu, de janeiro até o final de novembro de 2018, 295 operações contra desvios de dinheiro público. Foram 253 ações do tipo em 2017, 152 em 2016, 73 em 2015, 54 em 2014, 56 em 2013 e 48 em 2012. Destaca-se que a própria reportagem pontua que nas gestões passadas, a polícia classificava como operação apenas investigações de longa duração, consideradas complexas e, em geral, de impacto nacional. O conceito mudou durante a administração do ex-diretor Leandro Daiello, que passou a considerar operação toda ação da polícia que envolve pelo menos uma das seguintes medidas consideras invasivas: busca e apreensão, condução coercitiva e prisões.

14 Demanda de 514,84 candidatos por vaga no concurso de Agente de Polícia Federal de 2018. Fonte: Cebraspe.

15 Curso Básico de Investigação de Desvios de Recursos Públicos - 2017.02; Curso de Alinhamento Conceitual do PNLD (lavagem de dinheiro) - 2017.02; ATLAS SRDP - 2017.01. Fonte: ANP.net 
no Freire de Carvalho Calabrich (2010) aponta que supostos direitos fundamentais passaram a ser invocados com o único e exclusivo objetivo de criar novos óbices à aplicação da sanção penal. Para o referido estudioso, fala-se em supostos, devido a que estes direitos alegados se transmudam a um hipotético direito à impunidade, ao qual nenhum ordenamento posto racionalmente iria considerar.

Não obstante, a atividade policial na PF, ainda que pautada no enfrentamento vigoroso aos crimes de colarinho branco e fundamentada no princípio da seletividade, tem que respeitar os direitos fundamentais dos indivíduos para a consolidação do Estado de Direito, em que vige o império da lei.

$\mathrm{Na}$ atual conjuntura, em que a dinâmica da criminalidade assume uma feição cada vez mais complexa, intensa e marcada pela não linearidade, o desafio que se vislumbra para a atividade da polícia, em especial da PF, é a não compactuação, ainda que tácita, com a ilegalidade e a inconstitucionalidade sob o pretexto de um volúvel clamor popular ou uma pretensa eficiência.

Desse modo, a polícia deve refletir suas atribuições perante o prisma da igualdade material, fundada no eixo axiomático da dignidade da pessoa humana, a fim de contribuir para a legitimidade da consolidação do regime democrático e para a consecução do objetivo insculpido na Constituição Federal do Brasil de construção de uma sociedade livre, justa e solidária.

Fábio Caram Meireles

Agente de Polícia Federal. Pós-graduado em Comunicação Social (UFMG) Pós-Graduado em Ciências Policias pela Escola Superior de Polícia da ANP/PF.

Graduado em Direito pela Faceca e em Jornalismo PELO UNI-BH 


\title{
OFFENSIVE TO THE GOLDEN FIGURE OF CRIMINALITY: A CRIMINOLOGICAL LOOK AT the Brazilian Federal Police in the early 21ST CENTURY
}

\begin{abstract}
Through the history of formation and conformation of Brazil the criminological notion that, despite the fact that the national legal culture is based on a pretended equality, there is an impetuous discriminatory bias regarding the equal treatment of criminals for the population as a whole. Gradually, social vicissitudes have promoted an approximation of opportunity equality with ontological equality, among them a selective reformulation of the performance of criminal prosecution organs, with a view to legitimizing the state's repressive activity under the aegis of the rule of law. This paper demonstrates how the Brazilian Federal Police (PF) has altered its technical-investigative panorama, as well as the consequences of this novel performance in the social weaving.
\end{abstract}

KEYWORDS: police; law; criminology; white collar; economic crime.

\section{OFENSIVA A LA CIFRA DORADA CRIMINALIDAD:UNAMIRADACRIMINOLÓGICA al desempeño de la Policía Federal BRASILEÑA A PRINCIPIOS DEL SIGLO XXI}

\section{RESUMEN}

Hace parte de la historia de formación y conformación brasileña, la noción criminológica de que, aunque la cultura jurídica nacional se fundamente en una supuesta igualdad, existe un impetuoso sesgo discriminatorio en cuanto a la igualdad material de trato de los ámbitos criminal y penal para la población como un todo. Paulatinamente, las vicisitudes sociales han propiciado una aproximación de la igualdad formal y material, incluida una reformulación selectiva del papel de los órganos de persecución penal, con miras a legitimar la acción represiva estatal bajo la égida del Estado de derecho. Este artículo demuestra, con el aporte del soporte teórico criminológico, cómo la Policía Federal brasileña (PF) ha cambiado su panorama técnico-investigativo, así como las consecuencias de esta nueva actuación en el tejido social.

Palabras clave: policía; derecho; criminología; cuello blanco; delito económico. 


\section{REFERÊNCIAS}

ALMEIDA, Welder Oliveira. Pensamento complexo e transdisciplinaridade aplicados à ciência policial. Brasília: Revista Brasileira de Ciências Policiais, v.1, n. 2, 2010.

ALVAREZ, Marcos Cesar. A Criminologia no Brasil ou como tratar desigualmente os desiguais. Rio de Janeiro: Revista de Ciências Sociais, v. 45, n. 4, 2002.

ARANTES, Rogério Bastos. Polícia Federal e construção institucional. In: Corrupção e Sistema Político no Brasil. Rio de Janeiro: Civilização Brasileira, 2011.

BALDAN, Edson Luis (Org.). Ciências policiais e segurança pública. Goiânia: Ilumina, 2018.

BATISTA, Nilo. Punidos e mal pagos: violência, justiça, segurança pública e direitos humanos no Brasil de hoje. Rio de Janeiro: Revan, 1990.

BAYLEY, David H. Padrões de policiamento. Edusp, 2006.

CALABRICH, Bruno Freire de Carvalho. Pequenos mitos sobre a investigação criminal no Brasil. Salvador: Juspodivm, 2010.

CEBRASPE. Demanda de candidatos por vaga. Disponível em: https://cdn.cebraspe.org.br/concursos/PF_18/arquivos/PF_18_-DEMANDA.pdf. Acesso em: $14 \mathrm{dez} .2018$.

CORREIO BRAZILIENSE. Ações da PF contra corrup̧̧ão crescem $411 \%$ em cinco anos. Disponível em: https://www.correiobraziliense. com.br/app/ noticia/brasil/2018/07/02/interna-brasil,692246/ acoes-da-pf-contra-corrupcao-crescem-411-em-cinco-anos.shtml. Acesso em: 14 dez. 2018.

DALLARI, Dalmo de Abreu. Viagem incompleta: sociedade, estado e direito: caminhada brasileira rumo ao século XXI. São Paulo: Senac, 2000.

ELBERT, Carlos Alberto. A criminologia na pós-modernidade.

Ciências Penais, v. 14, 2011.

FERRAJOLI, Luigi. Direito e Razão. São Paulo: Revista dos Tribunais, 2002. 
las. O custo social da criminalidade econômica. In: SOUZA, Artur de Brito Gueiros (Org.). Inovaçôes no direito penal econômico: contribuições criminológicas, político-criminais e dogmáticas. Brasília: Escola Superior do Ministério Público da União, 2001.

GOMES, Paulo Valente. A actividade policial como ciência. Brasília: Revista Brasileira de Ciências Policiais, v. 1, n. 2, 2010.

GRANDIS, Rodrigo de. Prisóes processuais: uma releitura à luz do garantismo penal integral. Salvador: Juspodivm, 2010.

HABERMAS, Jürgen. Direito e democracia: entre facticidade e validade. Rio de Janeiro: Tempo Brasileiro, 1997.

IBOPE. Índice de Confiança Social 2018. Disponível em: http:// www.ibope inteligencia.com/arquivos/JOB\%2018_0741_ICS_ Apresenta\%C3\%A7\%C3\%A3o.pdf. Acesso em: 14 dez. 2018.

MARTIN, Luis Gracia. Prolegômenos para a luta pela modernização e expansão do direito penal e para a crítica do discurso de resistência. Porto Alegre: Sérgio Antonio Fabris Editor, 2006.

MOLINA, Antonio García-Pablos de. Problemas actuales de criminologia. Madrid: Instituto de Criminologia de la Universidad Complutense de Madri, 1984.

MORO, Sergio Fernando. Considerações sobre a operação Mani Pulite. Brasília: Revista do Centro de Estudos Judiciários, n. 26, 2004.

O GLOBO. Depois de bater recorde, Policia Federal prepara pelo menos 15 operações de combate à corrupção em dezembro. Disponível em: https://oglobo.globo.com/brasil/depois-de-bater-recordepolicia-federal-prepara-pelo-menos-15-operacoes-de-combatecorrupcao-em-dezembro-23268597. Acesso em: 14 dez. 2018.

OLIVEIRA, Adriano; ZAVIERUCHA, Jorge. A dinâmica da criminalidade organizada no Brasil a partir das operaçóes da PF. Dilemas. v. 5, n. 3, p. 423-446, 2012.

POLÍCIA FEDERAL. Estatística de operações. Disponível em: http://www.pf.gov.br/imprensa/estatistica/operacoes. Acesso em: 14 dez. 2018.

REINER, Robert. A Politica da Polícia. Edusp, 2004. 
SALGADO, Daniel de Resende. A elite do crime: discurso de resistência e laxismo penal. Salvador: Juspodivm, 2010.

SANTOS, Célio Jacinto. A gênese das grandes operações da Polícia Federal. Brasília: Revista Brasileira de Ciências Policiais, v. 8, n. 2, 2017.

SOUSA, António Francisco de. A polícia no estado de direito. São Paulo: Saraiva, 2009.

SUTHERLAND. Edwin. El delito de cuello blanco. Madri; La Piqueta, 1999.

VIANA, Eduardo. Criminologia. Salvador: Juspodivm, 2017.

WEBER, Max. Textos Selecionados. Ed. São Paulo: Nova Cultural, 1997.

YOUNG, Jock. Merton com energia, Katz com estrutura: a sociologia do revanchismo e a criminologia da transgressão. Revista Brasileira de Ciências Criminais, v. 87, 2010. 